RESEARCH

\title{
Modifying impact of RET gene haplotypes on medullary thyroid carcinoma clinical course
}

\author{
Marta Kaczmarek-Ryś1,*, Katarzyna Ziemnicka2,*, Andrzej Pławski1,3, Bartłomiej Budny², Michał Michalak4, \\ Szymon Hryhorowicz', Justyna Hoppe-Gołębiewska', Paweł Boruń1, Monika Gołąb², Małgorzata Czetwertyńska5, \\ Maria Sromek6, Marlena Szalata7, Marek Ruchała² and Ryszard Słomskí1,7 \\ 'Institute of Human Genetics, Polish Academy of Sciences, Poznan, Poland \\ 2Department of Endocrinology, Metabolism and Internal Diseases, Poznan University of Medical Sciences, Poznan, Poland \\ 3Department of General, Endocrinological Surgery and Gastroenterological Oncology, Poznan University of Medical Sciences, Poznań, Poland \\ ${ }^{4}$ Department of Computer Science and Statistics, Poznan University of Medical Sciences, Poznan, Poland \\ ${ }^{5}$ Department of Nuclear Medicine and Endocrine Oncology, Maria Skłodowska-Curie Institute - Oncology Centre, Warsaw, Poland \\ ${ }^{6}$ Department of Immunology, Maria Sklodowska-Curie Institute - Oncology Centre, Warsaw, Poland \\ ${ }^{7}$ Department of Biochemistry and Biotechnology, Poznan University of Life Sciences, Poznan, Poland \\ Correspondence should be addressed to M Kaczmarek-Ryś: m.kaczmarekrys@gmail.com \\ *(M Kaczmarek-Ryś and K Ziemnicka contributed equally to this work)
}

\section{Abstract}

The clinical course of medullary thyroid carcinoma (MTC) associated with the MEN2A syndrome as well as of sporadic MTC shows considerable heterogeneity. The disease picture varies not only between the same RET proto-oncogene mutation carriers but also among sporadic MTC patients with no RET germinal mutations, which suggests the involvement of additional modulators of the disease. However, genetic factors responsible for this heterogeneity of the MTC clinical course still remain unknown. The aim of this study was to determine if polymorphic variants or specific haplotypes of the RET gene may modify the MTC clinical course. We genotyped the following loci: c. $73+9277 T>C, c .135 G>A, c .1296 A>G, c .2071 G>A, c .2307 T>C, c .2508 C>T$ and c. $2712 C>G$ in 142 MTC patients and controls. We demonstrated considerable differences in the genotypes distribution within c.73+9277T >C, c. 135G >A and c.2307T>C loci. Our results show that the $c .73+9277 \mathrm{~T}$ variant associated with a decreased activity of the MCS+9.7 RET enhancer is rare in hereditary MTC patients with primary hyperparathyroidism, and thus, may influence the MTC clinical picture. The decreased activity of the RET promoter enhancer reduces RET expression level and may counterbalance the activating mutation in this gene. Frequent co-occurrence of the c.73+9277T allele with p.E768D, p.Y791F, p.V804M or p.R844Q RET mutations may be associated with their attenuation and milder clinical picture of the disease. Haplotypes analysis showed that C-G-A-G-T-(C)-C (c. $73+9277 \mathrm{~T}>\mathrm{C}-\mathrm{c} .135 \mathrm{G}>\mathrm{A}-\mathrm{c} .1296 \mathrm{~A}>\mathrm{G}-\mathrm{c} .2071 \mathrm{G}>\mathrm{A}-\mathrm{c} .2307 \mathrm{~T}>\mathrm{G}-(\mathrm{c} .2508 \mathrm{C}>\mathrm{T})-$ c. $2712 \mathrm{C}>\mathrm{G}$ ) alleles combination predisposes to pheochromocytomas and primary hyperparathyroidism. We consider that RET haplotypes defining may become an auxiliary diagnostic tool in MTC patients.

\author{
Key Words \\ - medullary thyroid \\ carcinoma \\ - MEN2 syndrome \\ - RET gene polymorphisms \\ - haplotypes \\ - associations analysis
}




\section{Introduction}

Medullary thyroid carcinoma (MTC) occurs sporadically (sMTC) or as an inherited cancer (hMTC). The hereditary form may be present as a component of the multiple endocrine neoplasia type 2 syndrome (MEN2) or as an isolated MTC without additional symptoms. However, while germinal mutations of the RET proto-oncogene have been shown to be closely associated with the hereditary form of MTC, the molecular bases of sporadic MTC remain unexplained (Elisei et al. 2007, Wells et al. 2015). Amino acid substitutions in the receptor tyrosine kinase (RET) increasing its activity occur mostly through mutations in the 3' part of the RET proto-oncogene. The mutations inducing a strong activation of the RET kinase are associated with more aggressive MTC forms, whereas those resulting in a weaker activation are reported to cause less aggressive MTC with a late onset. Moreover, the course of the disease frequently varies among carriers of an identical RET gene mutation as well as among family members, who are diagnosed at different ages, present disease of different aggressiveness, with or without such associated symptoms as pheochromocytoma (PHEO) and primary hyperparathyroidism (PHPT). This suggests the existence of other factors modifying the disease course (Qi et al. 2011, Sarika et al. 2012, 2015, Wells et al. 2015). Research aimed at finding such markers were initiated at the turn of the century. Da Silva et al. (2003) have described various MTC clinical courses in a multigeneration family and suggested a possible effect of singlenucleotide polymorphisms (SNPs) in the RET gene on the heterogeneous clinical course of the familial MTC. Some other reports have shown that RET genetic variants may be associated with a higher risk of aggressive early-onset sporadic MTC (sMTC) (Gimm et al. 1999, Ruiz et al. 2001, Berard et al. 2004, Elisei et al. 2004, Baumgartner-Parzer et al. 2005, Siqueira et al. 2010, Ceolin et al. 2016). Recent studies by Ceolin et al. (2016) have shown a significant correlation between polymorphisms in the $3^{\prime}$ UTR region and the secondary structure of the RET mRNA, suggesting their role in posttranscriptional control of the RET transcripts and disease presentation in MTC patients. Regarding this fact, it would be reasonable to expand the knowledge considering the proximal part of the gene. One of the most interesting polymorphisms in this part of the gene is c.73+9277T>C localized in intron 1. It was previously reported that this variation is situated within the MCS+9.7 enhancer region (Multispecies Conserved Sequence $9.7 \mathrm{~kb}$ downstream from the ATG codon) and that the c.73+9277T variant disrupts a binding site for
SOX10, which compromises RET transactivation and results in its transcriptional modulation (Emison et al. 2010). Formerly Emison et al. (2005) showed that the c.73+9277T allele in heterozygotes decreases activity of the RET gene enhancer, increasing the risk of the Hirschsprung's disease sixfold, and its homozygous state have even higher impact, rising risk 20 -fold. Hirschsprung's disease (aganglionic megacolon, HSCR) has a complex genetic etiology; however, inactivating mutations in the RET proto-oncogene are considered as the major HSCRcausing factors (Pan \& Li 2012).

In a study on the small group of MTC patients, the c.73+9277T allele has not been detected at all and the authors suggested its protective effect (Borun et al. 2012). More recently, RET overexpression has emerged as a new player in the ER-positive (ER+) breast cancer and as a potential target to enhance sensitivity and avoid resistance to tamoxifen treatment. Increased overall survival was observed in carriers of the c.73+9277T variant (Griseri et al. 2016).

In view of the fact that the contribution of RET SNPs and haplotypes to the development and progression of sporadic MTC remains not well evidenced and the authors of studies that have been published to date emphasize the necessity to continue research, we decided to investigate it.

The aim of this study was to determine the influence of polymorphic variants in the RET gene including the polymorphisms in the proximal region of the gene on clinical course of hereditary and sporadic MTC. The frequency of variants: c.73+9277T $>C$ (IVS1+9277T $>$ C, rs2435357) in intron 1, p.A45A (c.135G>A, rs1800858) in exon 2, p.A432A (c.1296A>G, rs1800860) in exon 7, p.G691S (c.2071G>A, rs1799939) in exon 11, p.L769L (c.2307T>C, rs1800861) in exon 13, p.S836S (c.2508C >T, rs1800862) in exon 14 and p.S904S (c.2712C>G, rs1800863) in exon 15 were determined in group of 142 patients with MTC and population control. An association of particular alleles and genotypes with the clinical course of the disease were studied. We have also analyzed the linkage disequilibrium and the correlations of the RET gene haplotypes with the MTC clinical picture, and the presence of particular RET mutations in association with the haplotypes.

\section{Materials and methods}

\section{Patients and controls}

We studied DNA samples from a group of 142 patients with MTC from the Great Poland (Wielkopolska) region, 
who have been hospitalized in The Department of Endocrinology, Metabolism and Internal Diseases of Poznan University of Medical Sciences in Poland. The group included 51 patients with hereditary MTC and diagnosed RET gene mutations (Fig. 1 and Supplementary Table 1 , see section on supplementary data given at the end of this article), and 91 sporadic cases with RET germinal mutations excluded. Data on the presence of somatic mutations in patients with sMTC were not available.

The demographic and clinical data included gender, age at diagnosis, histopathological examination results with the evaluation of multifocality, the TNM classification and in patients with hereditary MTC also the presence of comorbid diseases: pheochromocytoma (PHEO) and primary hyperparathyroidism (PHPT) were collected (Supplementary Table 1). Controls were unrelated individuals from the Polish population who were received at the Laboratory of Molecular Genetics (Poznan, Poland) for paternity testing. Depending on the tested polymorphism, the control group consisted of 204-678 individuals. All subjects signed an informed consent to genetic testing, and the study was approved by the Ethical Committee of Poznan University of Medical Sciences.

\section{Genetic analyses}

Genomic DNA was extracted from peripheral blood using guanidine isothiocyanate and following phenol-chloroform extraction using a standard protocol (Słomski 2008). Isolates were dissolved in $1 \times$ TE buffer and stored at $-20^{\circ} \mathrm{C}$ until analysis. Then, SNPs in the RET gene were analyzed by pyrosequencing or high-resolution melting analysis (HRMA) and Sanger sequencing. Primers were designed using PyroMark Assay Design Software 2.0 (Biotage) and Primer 3 online primer design tool (all primer sequences and melting temperatures are listed in Supplementary Table 2). Templates for pyrosequencing were amplified by PCR as follows: a 5-min initial denaturation at $94^{\circ} \mathrm{C}$, then 50 cycles of $94^{\circ} \mathrm{C}$ for $30 \mathrm{~s}$, annealing for $30 \mathrm{~s}$ and $72^{\circ} \mathrm{C}$ for $60 \mathrm{~s}$, followed by a 5 -min final elongation at $72^{\circ} \mathrm{C}$. Pyrosequencing reactions were performed on the PSQ96 apparatus using PyroMark Gold Q96 reagents kits (Qiagen) according to the manufacturer's recommendations. HRM analyses were run on the Rotor-Gene Q cycler using the Type-it HRM PCR Kit (Qiagen). The DNA fragments containing the RET gene exons were amplified by PCR $\left(5 \mathrm{~min}\right.$ at $95^{\circ} \mathrm{C}$, then 40 cycles as follows: $95^{\circ} \mathrm{C}$ for $10 \mathrm{~s}, 60^{\circ} \mathrm{C}$ for $30 \mathrm{~s}$ and $72^{\circ} \mathrm{C}$ for $10 \mathrm{~s}$ ) and the products were subsequently melted from 75 to $95^{\circ} \mathrm{C}$ by raising the temperature by $0.1^{\circ} \mathrm{C}$ at each step. Sanger sequencing was performed on MegaBACE 500 (GE Healthcare) or ABI PRISM 3100 (Applied Biosystems).

\section{Statistical analyses}

The comparison of the age of diagnosis between the two groups (hereditary vs sporadic) as well as

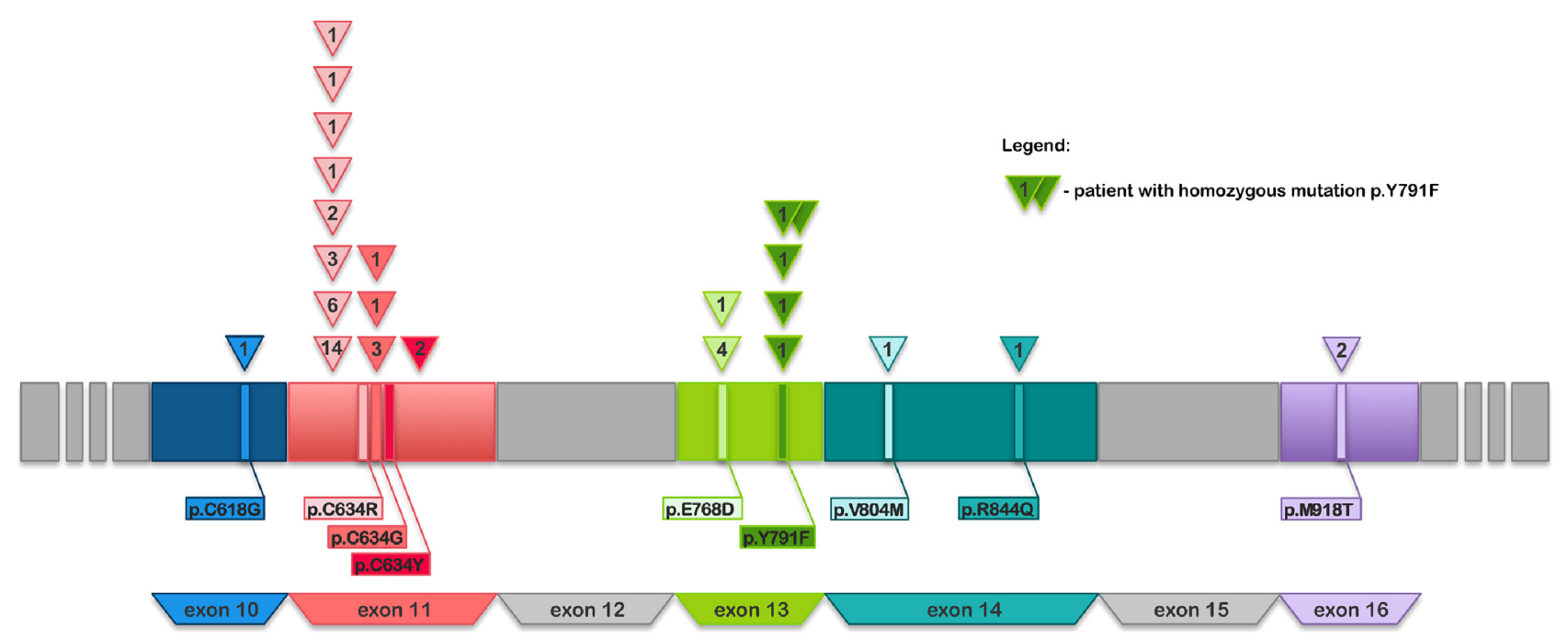

Figure 1

A diagram showing a fragment of the RET gene, where MTC-related mutations are most common. Mutations identified in the study group were marked. The triangles represent individual families, while the numbers in the middle of the triangles indicate the number of family members who inherited the mutation. 
between particular alleles was conducted using the Mann-Whitney test because the data did not have a normal distribution as shown by the Shapiro-Wilk test. The comparison of age of diagnosis between genotypes was performed by Kruskal-Wallis test. The nominal scale variables were analyzed using the chi-square independence test or - in case of low observation numbers - Fisher's exact test. Odds ratio (OR) with 95\% confidence intervals (CI) and $P$ values were also calculated. $P$ values below 0.05 were considered as indicative of statistical significance.

All statistical analyses were conducted using Statistica10.0 (StatSoft) and GraphPad 3.06 (GraphPad Software). The concordance with Hardy-Weinberg equilibrium was tested using the calculator on the following website: https://ihg.gsf.de/cgi-bin/hw/ hwa1.pl. $P$ values for HWE were returned by Pearson's chi-square test of independence. In case one of the alleles was not present in the study group, a correction has been applied by adding 0.5 values to each count, according to Deeks \& Higgins (2010).

\section{Linkage disequilibrium analysis}

The analysis of the linkage disequilibrium for the polymorphisms under study and of the associations between the haplotypes and the clinical data was conducted using the Haploview v.4.2 software (Barrett et al. 2005).

\section{Ethical approval}

The study was approved by the Bioethical Committee of the University of Medical Sciences in Poznań, Poland, under Resolution No. 627/07 and 829/13. Informed consent was obtained from every participant.

\section{Results}

In hereditary MTC patients, we have identified 9 different mutations in RET gene in exons: 10, 11, 13, 14 and 16. The most frequent were alterations in codon 634 (Fig. 1 and Supplementary Table 1). Demographic and clinical characteristics of hereditary and sporadic MTC patients compared to controls are summarized in Table 1. Both hereditary and sporadic cases were slightly more frequent in women $(56.9 \%$ and $63.7 \%)$. The average age at diagnosis was statistically lower in patients with hereditary MTC (34.4 vs 52.9; $P$-value $<0.001$ ); patients who were diagnosed before symptoms appeared were excluded from these analyses. Sporadic MTC patients presented with a more advanced disease at diagnosis, with a higher proportion of individuals with tumors in $\mathrm{T} 3$ and $\mathrm{T} 4$ stages (35\% of sporadic vs $21.6 \%$ hereditary MTC patients). Also lymph nodes metastases seemed to be more frequent in sporadic MTC patients (46.3\% vs $37.8 \%$ ), as were distant metastases (10\% vs $5.4 \%$ ), but these observations were not statistically significant. Multifocality was five times more frequent in hereditary MTC patients than in sporadic cases $(\mathrm{OR}=5.5 ; \mathrm{CI}=2.18-14.99 ; P$ value $<0.001)$.

Table 1 Basic characteristics of examined MTC patients - hereditary vs sporadic cases.

\begin{tabular}{|c|c|c|c|c|}
\hline & \multicolumn{2}{|c|}{ Hereditary MTC } & \multicolumn{2}{|c|}{ Sporadic MTC n (\%) } \\
\hline & $n(\%)$ & $n$ total ${ }^{* *}$ & $n(\%)$ & $n$ total** \\
\hline \multicolumn{5}{|l|}{ Sex } \\
\hline Females & $29(56.9)$ & 51 & $58(63.7)$ & 91 \\
\hline Males & $22(43.1)$ & & $33(36.3)$ & \\
\hline Age at diagnosis (mean \pm S.D. $\left.{ }^{*}\right)$ & $34.4 \pm 13.8$ & 40 & $52.9 \pm 15.5$ & 88 \\
\hline \multicolumn{5}{|l|}{ Tumor stage } \\
\hline \multicolumn{5}{|l|}{$\mathrm{T}$} \\
\hline $\mathrm{T} 1+\mathrm{T} 2$ & $29(78.4)$ & 37 & $52(65.0)$ & 80 \\
\hline $\mathrm{T} 3+\mathrm{T} 4$ & $8(21.6)$ & & $28(35.0)$ & \\
\hline \multicolumn{5}{|l|}{$\mathrm{N}$} \\
\hline No & $23(62.2)$ & 37 & $43(53.8)$ & 80 \\
\hline N1 & $14(37.8)$ & & $37(46.3)$ & \\
\hline \multicolumn{5}{|l|}{ M } \\
\hline Mo & $35(94.6)$ & 37 & $72(90.0)$ & 80 \\
\hline M1 & $2(5.4)$ & & $8(10.0)$ & \\
\hline Multifocality & $15(40.6)$ & 37 & $10(11.2)$ & 89 \\
\hline Pheochromocytoma (PHEO) & $22(47.8)$ & 46 & 0 & - \\
\hline Primary hyperthyroidism (PHPT) & $8(17.8)$ & 45 & 0 & - \\
\hline Other malignancies & $1(2.2)$ & 45 & $7(7.9)$ & 89 \\
\hline \multicolumn{5}{|l|}{ *S.D., standard deviation. } \\
\hline
\end{tabular}


Pheochromocytomas and primary hyperparathyroidism were observed only in hereditary MTC patients.

In an analysis of allele and genotype distribution, we have observed a discordance with Hardy-Weinberg equilibrium among sporadic MTC patients, with statistically significant differences in the genotype distribution between the studied groups for the following four polymorphisms: c.73+9277T $>C$, c.135G $>A$, c.1296A $>\mathrm{G}$ and c.2307T>G (Table 2).

We have shown a significant inverse correlation between the c.73+9277T allele and primary hyperparathyroidism: the $\mathrm{T}$ allele had a protective effect $(\mathrm{OR}=0.12 ; \mathrm{CI}=0.02-0.98 ; P$ value $=0.032)$, while allele $\mathrm{C}$ was risk allele $(\mathrm{OR}=8.13 ; \mathrm{CI}=1.02-65.02 ; P$ value $=0.032)$. Similarly, the c.135A allele was less frequent among patients with PHPT $(\mathrm{OR}=0.13 ; \mathrm{CI}=0.01-1.05)$, while c.135G allele predisposed to $\mathrm{PHPT}(\mathrm{OR}=7.65 ; \mathrm{CI}=$ 0.96-61.31), but this association was borderline significant $(P$ value $=0.055)$ (Table 3$)$. The analyses performed for sporadic cancer patients showed that the c.73+9277T $>C$ variants have a higher frequency of the c.73+9277C allele $(\mathrm{OR}=2.43 ; \mathrm{CI}=1.07-5.53 ; P$ value $=0.035)$ as well as of the wild-type homozygotes (CC) among patients with tumors at advanced stages (T3 and T4) at diagnosis $(P$ value $=0.051) \quad($ Table 4$)$. However, we have made no corrections for the multiple statistical testing.

Imputing genotype data to the Haploview v.4.2 software (Fig. 2 and Supplementary Table 3), we observed a strong linkage disequilibrium $\left(\mathrm{D}^{\prime}=1\right)$ for the following sets of polymorphisms: c.73+9277T $>C$ and c.135G $>A$, c. $73+9277 \mathrm{~T}>\mathrm{C}$ and c.2071G $>\mathrm{A}, \quad$ c. $73+9277 \mathrm{~T}>\mathrm{C}$ and c. $2712 \mathrm{C}>\mathrm{G}, \mathrm{c} .2307 \mathrm{~T}>\mathrm{G}$ and c.2508C $>\mathrm{T}$ (only in sporadic MTC patients), and c.2071G $>$ A and c.2712C $>$ G. However, the corresponding values of the $r^{2}$ factor $(>0.8)$ were found only for the following pairs of polymorphisms: c. $73+9277 \mathrm{~T}>\mathrm{C}$ and c.135G $>$ A among hereditary MTC patients, and c.2071G $>$ A and c. $2712 \mathrm{C}>\mathrm{G}$ among sporadic MTC patients. In both groups, the most frequent allele combination was as follows: C-G-G-G-T-C-C and C-G-GA-T-C-G (Fig. 2 and Supplementary Table 3). The analysis of correlations between the haplotypes and the clinical course of the disease has shown that the C-G-A-G-T-(C)-C (c.73+9277T >C - c.135G $>$ A - c. $1296 \mathrm{~A}>\mathrm{G}-$ c.2071G $>\mathrm{A}-$ c.2307T $>\mathrm{G}-($ c. $2508 \mathrm{C}>\mathrm{T})-$ c.2712C $>\mathrm{G})$ haplotype may predispose to pheochromocytoma $(\mathrm{OR}=3.41 ; \mathrm{CI}=$ 1.57-7.40; $P \quad$ value $=0.002$ ) and primary hyperparathyroidism $\quad(\mathrm{OR}=4.37 ; \quad \mathrm{CI}=1.56-12.28$; $P$-value $=0.005)$. This haplotype was also more common in patients with the disease diagnosis set before 40 years of age $(\mathrm{OR}=1.96 ; \mathrm{CI}=1.01-3.87 ; P$ value $=0.049)$ and in
individualswithmultifocalMTC $(\mathrm{OR}=3.17 ; \mathrm{CI}=1.03-10.26$; $P$ value $=0.044)($ Table 5) .

As pheochromocytomas and PHPT are characteristic for the MEN2A syndrome in hereditary MTC patients, we have also analyzed the presence of RET mutations on haplotype backgrounds. We have found a strong link of mutations in codon 634 with the C-G-T allele combination (c.73+9277T $>C$ - c.135G $>$ A - c.2307T $>$ G) $(\mathrm{OR}=4.58 ; \mathrm{CI}=1.75-11.90 ; P$ value $=0.002)$, while they were rare in association with haplotype block T-A-G $(\mathrm{OR}=0.18 ; \mathrm{CI}=0.06-0.51 ; P$ value $=0.001)$. When focusing only on the most frequent mutation p.C634R alone, the association was even stronger, with the OR of 5.65 $(\mathrm{CI}=2.27-14.04 ; P$ value $<0.001)$ for the C-G-T haplotype block, and $0.11(\mathrm{CI}=0.03-0.04 ; P$ value $<0.001)$ for the alternative combination, T-A-G. In contrast, the mutations associated with hereditary isolated MTC (p.E768D, p.Y791F and p.V804M, p.R844Q) co-existed rarely with the C-G-T haplotype block ( $\mathrm{OR}=0.16$; $\mathrm{CI}=0.06-0.47$; $P$ value $<0.001)$ and frequently with the T-A-G allele combination $(\mathrm{OR}=4.50 ; \mathrm{CI}=1.54-13.18 ; P$ value $=0.006)$ (Table 6).

\section{Discussion}

Many mutations of the RET proto-oncogene leading to MTC and the MEN2 syndrome have been identified so far. However, it is still not known why patients presenting the same genetic alteration vary significantly on clinical course of the disease. Studies beyond routine diagnostics of the most frequent mutations have identified several polymorphisms that may be involved; however, their influence on the clinical course of the disease is not yet clearly understood.

The $\quad$ c.73+9277T>C $\quad$ (IVS1+9277T $>C, \quad$ rs2435357) polymorphism is localized in intron 1 of the RET gene, within the MCS enhancer located $9.7 \mathrm{~kb}$ from the ATG codon and the presence of one copy of c.73+9277T allele was found to be clinically relevant, causing a sixfold decrease in the RET gene enhancer activity (Emison et al. 2005,2010 ). In our study, genotype distribution in this locus has shown that the TT genotype was six times more frequent in hereditary MTC patients than in sporadic cases and four times more frequent among controls than in sMTC cohort. These findings may suggest a protective effect of the TT genotype against sporadic MTC.

To the best of our knowledge, an association between the c.73+9277T $>$ C polymorphism and the MTC course has never been reported. In our study, we have observed a higher frequency of the CC (wild-type) genotype in 


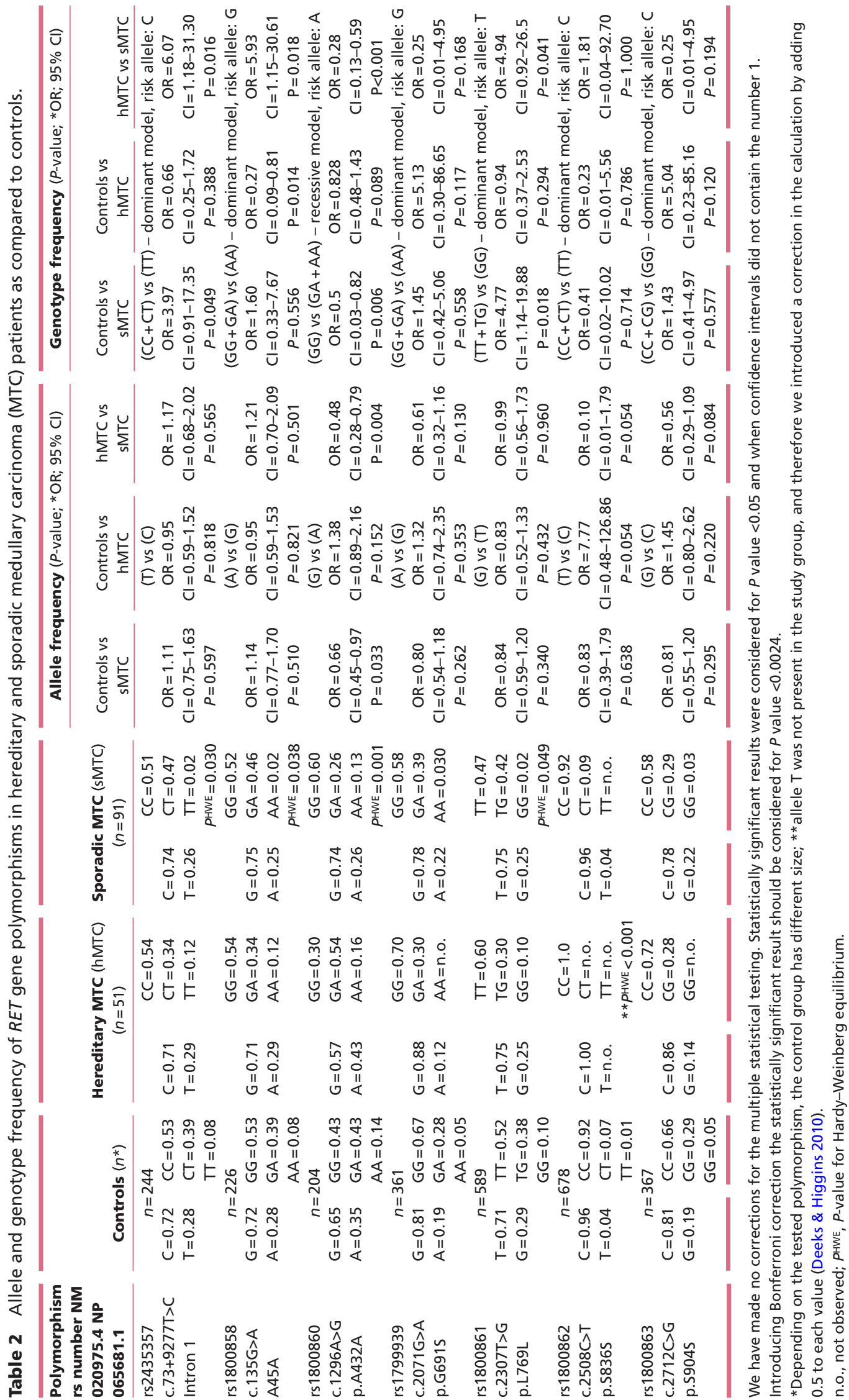


patients with advanced sporadic MTC (T3 and T4), including patients with metastases. This suggests that lower RET gene expression levels associated with the TT genotype counterbalances an increase in the RET kinase activity and thus alleviates the disease. That would explain our observation that wild-type CC homozygote genotype is more frequent in sporadic MTC patients with a more severe disease: earlier onset, larger tumor size and metastases at the moment of diagnosis.

The c.135G>A (p.A45A, rs1800858) polymorphism in exon 2 of the RET gene had been described in four publications (Gimm et al. 1999, Cebrian et al. 2005, Fernandez et al. 2006a, Fugazzola et al. 2008). In a metaanalysis compiling the results of these studies, Figlioli et al. (2013) determined the average frequency of the c. $135 \mathrm{~A}$ allele to be $18.5 \%$ in patients and $23.6 \%$ in the population controls. In our study, we have found a lower frequency of the c.135A allele in sporadic MTC patients $(25.3 \%)$ than in hMTC patients $(29.0 \%)$ and controls (27.9\%). The AA genotype was significantly more frequent in hMTC patients (12.0\%) than in sporadic MTC patients (2.2\%). Moreover, c.135A allele was present in only $18.1 \%$ sMTC patients with $\mathrm{T} 3$ and $\mathrm{T} 4$ tumors in comparison with $30.4 \%$ in patients presenting $\mathrm{T} 1-\mathrm{T} 2$ tumors. This finding might suggest a protective effect of the c.135A allele. In patients with the hereditary form of the disease, we have observed an association of the c.135G allele with the primary hyperparathyroidism and the c.135A allele was present only in one out of eight patients with diagnosed PHPT.

Similar to c.73+9277T, the c.135A variant has been shown to be associated with an increased risk of developing the Hirschsprung's disease (Borrego et al. 1999, Carter et al. 2012, Vaclavikova et al. 2014). Studying genetic factors associated with susceptibility to sMTC, Cebrian et al. (2005) observed a protective effect of the c.135A allele. They found the presence of this allele in a haplotype that was not associated with sMTC. The authors suggested the involvement of another variant also being in linkage disequilibrium with c.135G $>$ A, which may be localized in the region of the promoter or regulatory elements of the RET gene. Haplotype analysis conducted in this study for sporadic MTC patients has shown a nearly complete linkage disequilibrium between the c.135G $>$ A and c.73+9277T $>C$ variant. Taking all this into consideration, we conclude that c. $73+9277 \mathrm{~T}>\mathrm{C}$ is a functional variant, which may influence the clinical course of MTC.

The analysis of the c.1296A>G (p.A432A, rs1800860) polymorphism has shown that the c.1296A allele was significantly less common among sporadic MTC patients as compared to the control group and to hMTC individuals. However, in this sole case, the frequency of the wild-type c.1296G allele obtained for the Polish population in our study was higher than the minor allele frequency (MAF) in the NCBI database (35.3\% vs $22.5 \%)$. This discrepancy may result from a relatively small size of the group analyzed for this polymorphism in our study (204 individuals). Recent study on the Czech population has shown a similar frequency of the c.1296G allele: $33.9 \%$ and its significantly lower occurrence in HSCR patients (25.8\%) (Vaclavikova et al. 2014). It is worth to emphasize that in this study, we found a significantly higher frequency of the c.1296A allele in hMTC patients as compared to sporadic MTC cohort. Moreover, the AA and GA genotypes in sporadic patients were considerably less common than those in population-based controls. However, there have been no reports describing this polymorphism in MTC patients.

The c.2071G>A (p.G691S, rs1799939) polymorphism in exon 11 of the RET gene is particularly interesting, bearing in mind its functional implication. This variant is frequently detected during routine MTC diagnostics and therefore abundantly reported in the literature. The c.2071A allele was associated with an aggressive course of pancreatic cancer (Sawai et al. 2005, Donahue \& Hines 2009). It has also been shown to be frequent in cell lines derived from neuroendocrine lung tumors (Sosonkina 2014). Cebrian et al. (2005) and Elisei et al. (2004) evidenced an association between the c.2071A allele and sMTC. In an in silico analysis, Lantieri et al. (2013) found that the presence of the c.2071G>A variant changes the phosphorylation pattern of the RET protein, which may result in an induction of signal transduction and hyperactivation of the RAS/ERK pathway. These authors also determined the frequency of this polymorphism among Italian patients and showed differences between MTC patients and the general population. However, these were not statistically significant. In a meta-analysis of eleven studies, they showed that the c.2071A variant represents a low-penetrance allele that predisposes to MTC and may also affect the metastatic capacities and the aggressiveness of the tumor. In our study, we did not found statistically significant differences in frequencies of the c.2071G $>$ A polymorphic variants between examined groups; nevertheless, the c.2071A allele seemed to appear a bit more frequently in sporadic than in hereditary MTC patients $(22.5 \%$ vs $15 \%)$ and also a bit more often than in the control population group ( $22.5 \%$ vs $18.8 \%)$. We have not confirmed an association of the c.2071A allele with 


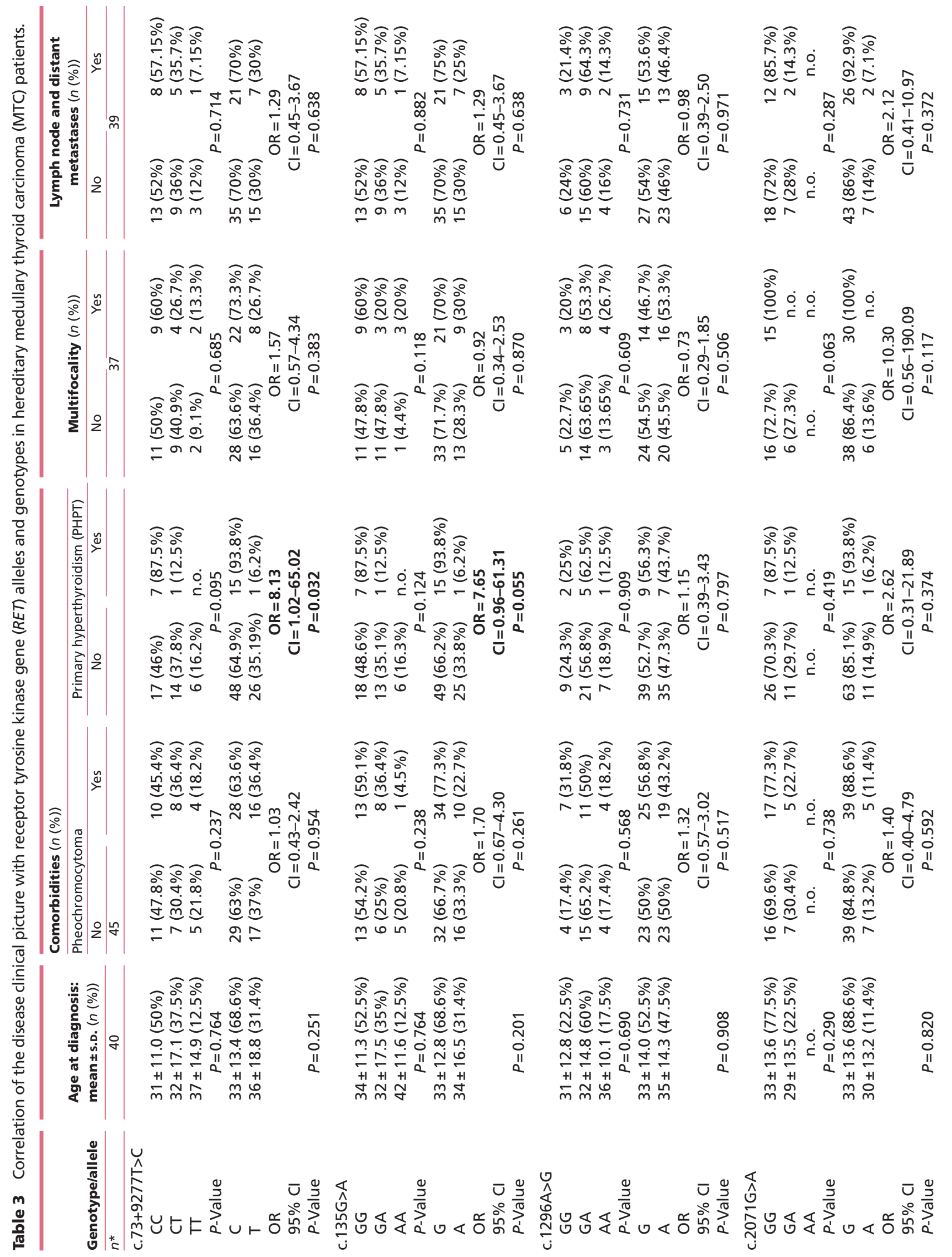




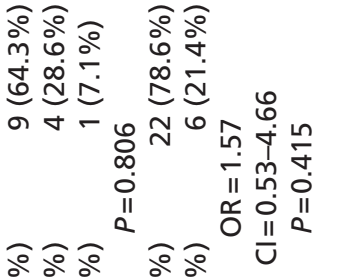

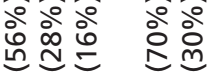

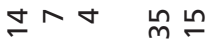

ㅇํㅇ वें

०ิ

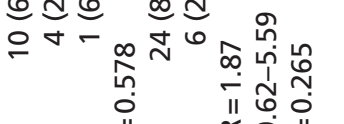

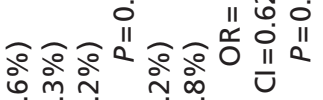

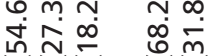

다

仓ัo

a $\stackrel{\substack{n \\ \infty}}{2}$

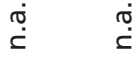

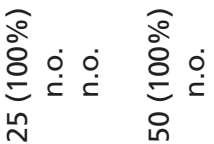

六官

는

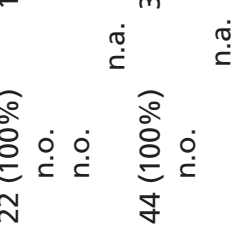

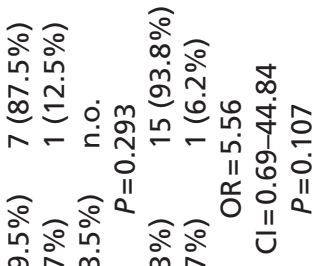

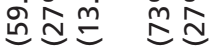

N은 냉유

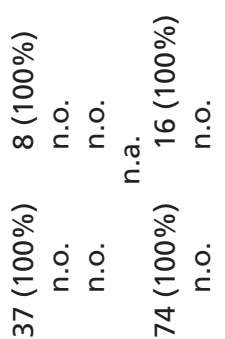

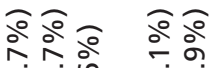

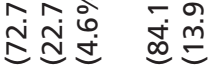

on-

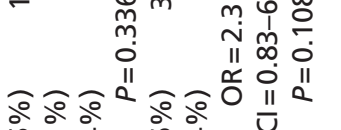

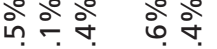

它

mor

ㅇํㅇ ㅇํㅇ

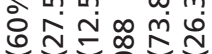

$m \infty \circ m \infty$

둥요

$\stackrel{n+1}{+1+1}+\underset{+1}{+1}$

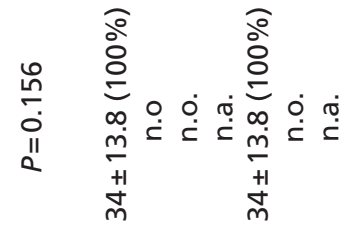

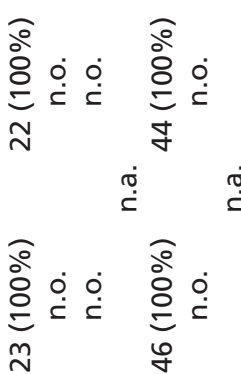

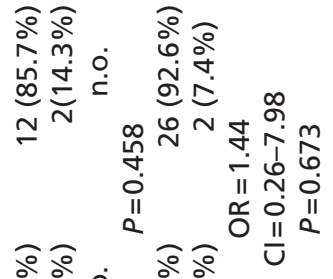

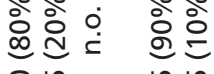

$i^{\text {in }} \quad$ 年

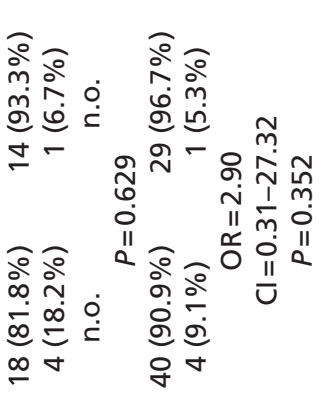

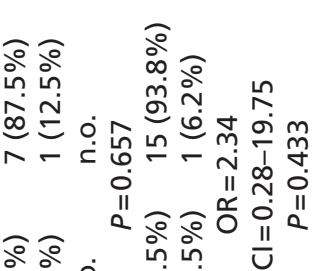

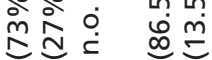

드응

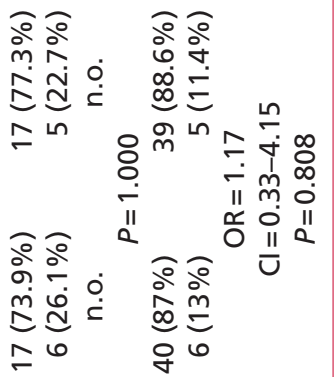

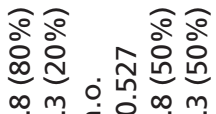

$\stackrel{\infty}{\underline{m}} \stackrel{m}{m} \stackrel{\dot{m}}{\prime} \| \stackrel{\infty}{\underline{m}} \stackrel{m}{\underline{m}}$

mit $\stackrel{+1}{++1}$

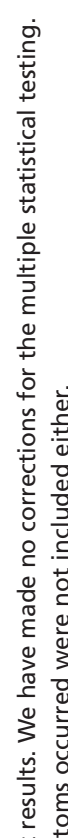

ते

施

可

잉

용

잉

罂

웜

美学

i

苋

较

iI

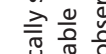

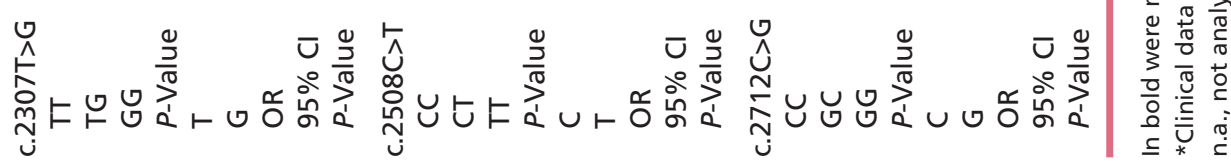




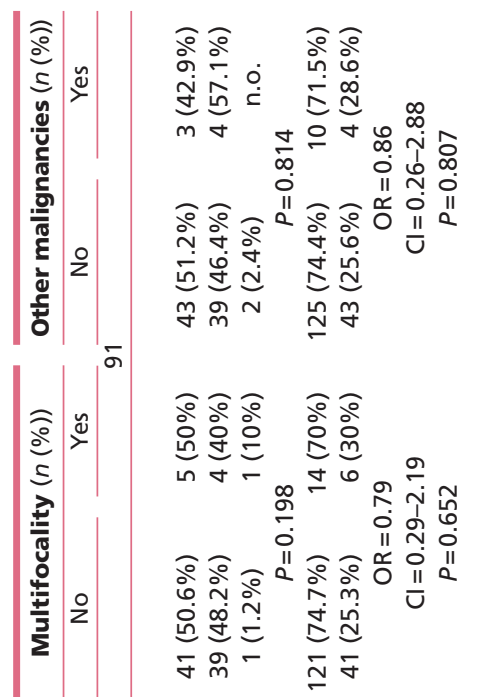

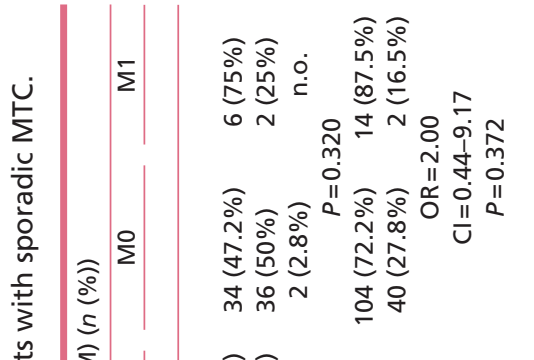

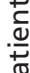

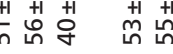

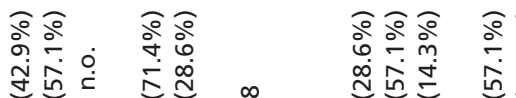

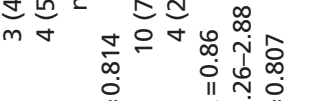

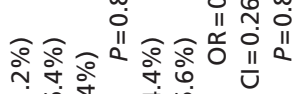

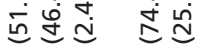

mั่

ㅇํㅇ ㅇํㅇ

过㝘宮

$\checkmark$ 㧒

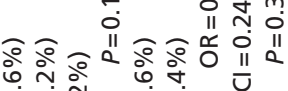

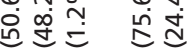

₹ $\stackrel{\infty}{-} \overline{\check{\tau}}$

ㅇํㅇํำ ㅇํㅇ

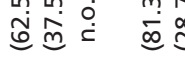

n

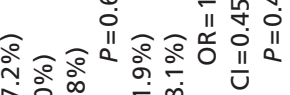

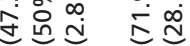

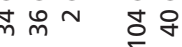

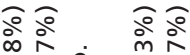

نู

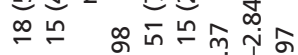

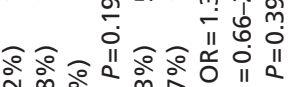

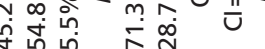

$\tilde{N} \sim$ oิ

वें

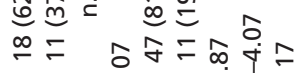

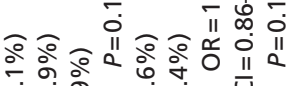

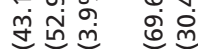

$\tilde{N} \tilde{N}^{N} \bar{m}$

ㅎํㅇㅎㅇ

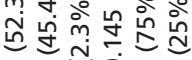

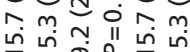

$+1+10+1$

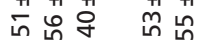

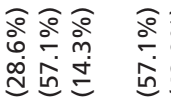

N

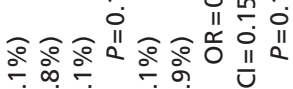

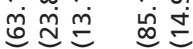

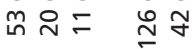

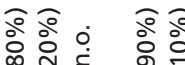

$\infty_{\infty}^{\infty} \underset{N}{\infty}=0$

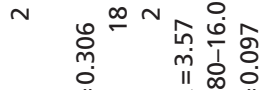

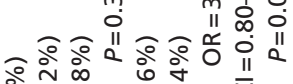

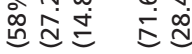

子 $\mathcal{N} \simeq$

ㅇํㅇㅎㅇㅎํ

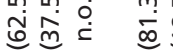

in $m \quad$ o m m

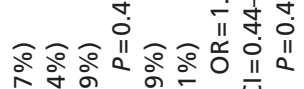

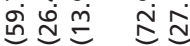

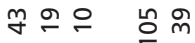

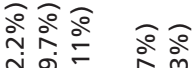

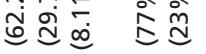

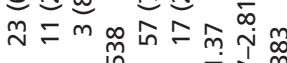

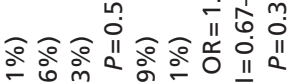

क्ष

느는

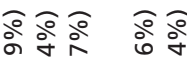

क⿺辶一்

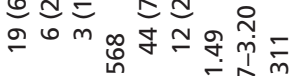

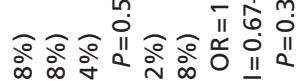

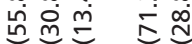

은

ํํำ วัे

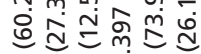

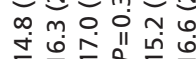

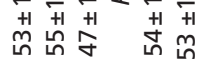

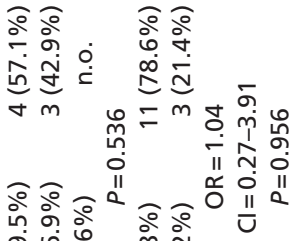

म्रु

员 $\bar{m}$ 兹

क्षे

$6+0 \stackrel{\sigma}{0} 0$

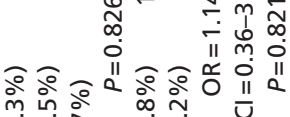

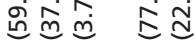

字售

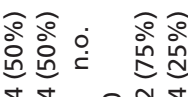

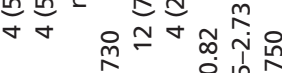

๙

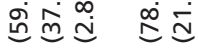

$\eta \hat{N}^{N} \stackrel{m}{=} \bar{m}$

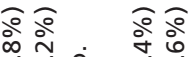

岂莳寽

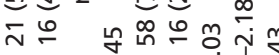

N

๖ें

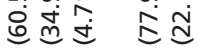

는 능

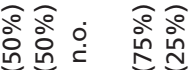

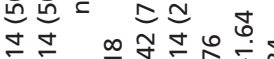

กิ oi 1.

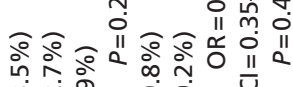

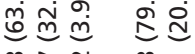

$m=N \quad m \bar{N}$

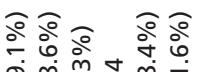

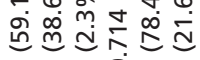

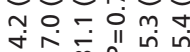

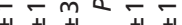

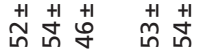

$\hat{N}$

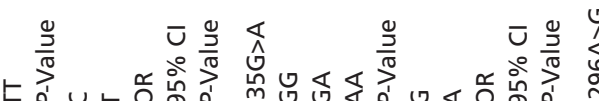

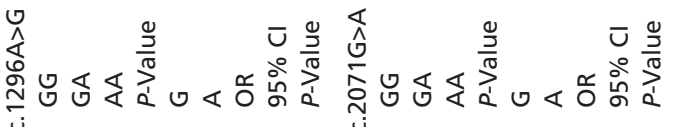




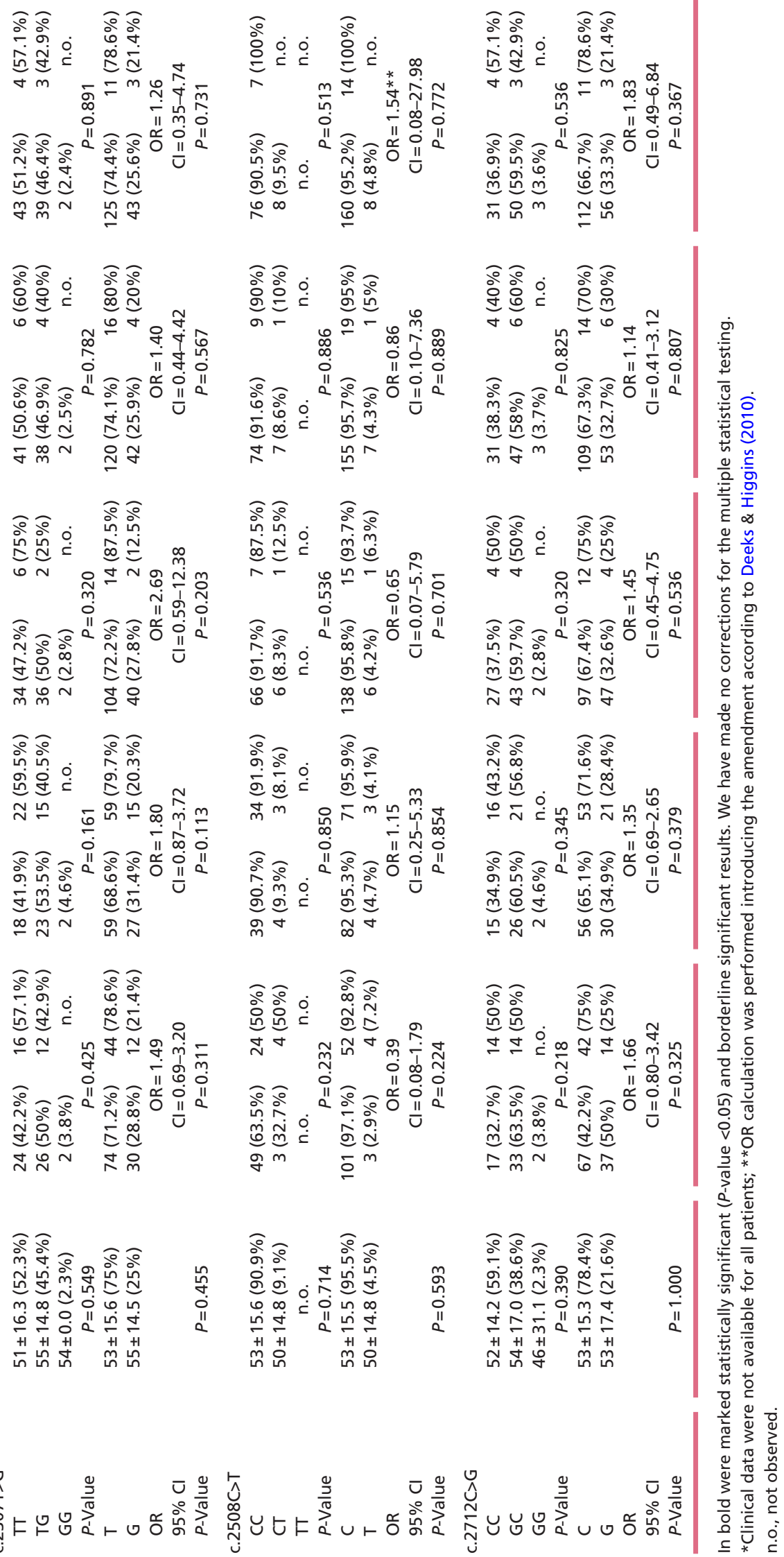


A

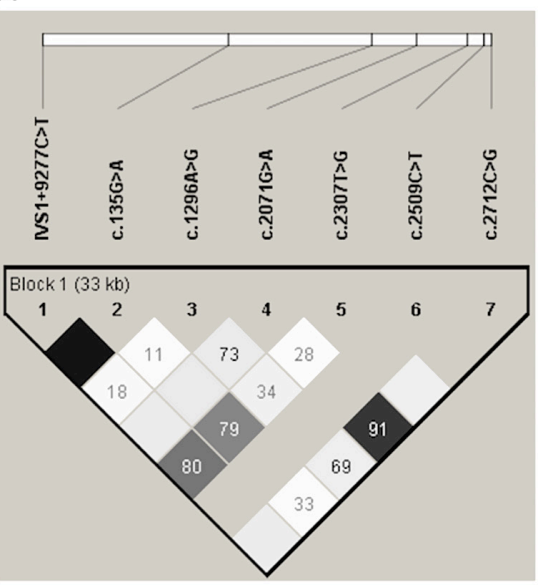

B

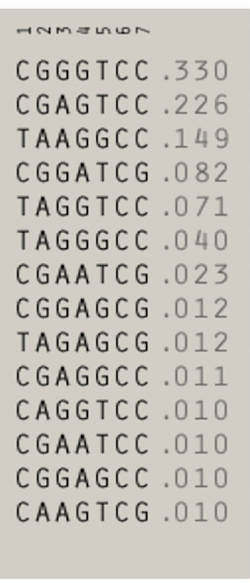

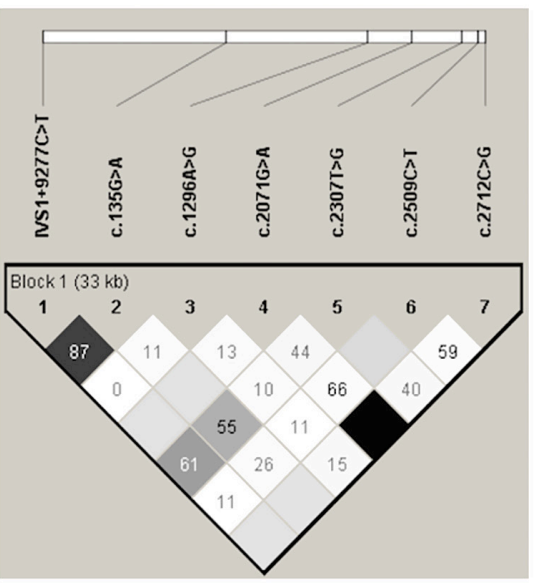

hamangen CGGGTCC .341 CGGATCG.144 CGAGTCC.108 TAAGGCC .074 TAGGTCC .069 TAGGGCC.066 CGAATCG.056 CGGGGCC.028 TGGGGCC .023 CGGGGTC .020 TAGGGTC .013

\section{Figure 2}

Linkage disequilibrium (LD) plots; (A) patients with hereditary MTC, (B) patients with sporadic MTC. The LD plots were constructed with Hap/oview v.4.2 software (Barrett et al. 2005). Numbers in squares represent the $D^{\prime}$ statistic $\times 100$ for each pairwise comparison, if $D^{\prime}=1$ the squares are shaded only. Gray color intensity indicates the intensity of $r^{2}\left(r^{2}=0\right.$ : white, $0<r^{2}<1$ : shades of gray, $r^{2}=1$ : black). Haplotypes frequencies are shown on the right.

an earlier onset of the disease that was reported by other researchers (Robledo et al. 2003, Cardot-Bauters et al. 2008).

Other studies indicated a strong linkage disequilibrium (LD) between the c.2071G >A and c.2712C>G (p.S904S, rs1800863) polymorphisms in exon 15 (Robledo et al. 2003, Elisei et al. 2004, Cebrian et al. 2005, Fernandez et al. 2006b, Fugazolla et al. 2008, Siqueira et al. 2010, Machens et al. 2012, Lantieri et al. 2013). The analysis using the Haploview software we conducted in this study has also confirmed strong LD in patients with the hereditary form of MTC $\left(r^{2}=0.770 ; \mathrm{D}^{\prime}=0.914\right)$ and complete linkage disequilibrium in sMTC patients $\left(r^{2}=0.969 ; \quad \mathrm{D}^{\prime}=1\right)$. Therefore, we conclude that the genotype distribution and the allele frequencies of the c.2712C>G were similar to c. $2071 \mathrm{G}>\mathrm{A}$. These results are in accordance with those, reported by Fugazzola et al. (2008) and Machens et al. (2012), who found any association between the G691S/ S904S variants and an increased risk or the clinical course of sMTC form.

In contrast, we observed an incomplete linkage equilibrium between c.73+9277T $>C$ and c.135G $>A$ polymorphisms localized in the $5^{\prime}$ region of the RET protooncogene and c.2307T>G (p.L769L, rs1800861) variant localized in exon 13 of the RET gene. We have observed a lower prevalence of rare homozygotes among patients with sporadic MTC as compared to hereditary cases and to the controls. Moreover, we found statistically significant differences in genotype distribution between sMTC patients and controls, with the heterozygous TG genotype of c. $2307 \mathrm{~T}>\mathrm{G}$ polymorphic variant being more frequent in sporadic patients $(46.2 \%)$ than in hMTC patients $(30.0 \%)$ and in controls (40.4\%). This was in accordance with the results reported for patients from central Poland in whom the heterozygous c.2703T>G variant was found in $48.3 \%$ cases as compared to $39.5 \%$ in healthy individuals. The authors also reported that this variant predisposes to sporadic MTC. Their computer simulations also showed that the c.2703G allele may influence mRNA stability by reducing its minimal free energy (MFE) by $17 \%$ for the wild-type, $7 \%$ for the p.Y791F mutant and less than 5\% for the c.2712C>G and c.2508C>T variants as well as for the most frequent p.C634R mutation (Sromek et al. 2010). We did not observed an association between the c.2703G allele with a younger age at diagnosis, which was suggested by Sromek et al. (2010), nor with pheochromocytoma or PHPT. On the contrary, this allele seemed to have a protective effect: it was present in only one PHPT patient (6.2\% vs $27 \%$ among other patients) and in six out of twenty-two pheochromocytoma patients (13.9\% vs $30.4 \%$ in other patients), but these results were not statistically significant. Any significant associations in sporadic MTC cohort were found either. Nonetheless, we observed a slightly lower frequency of the c.2703G allele in patients with more advanced disease (T3 and T4) and metastases (N1 and M1) present at the time of diagnosis. Our results do not allow to draw univocal conclusions so as to the influence of the c.2307T>G polymorphism on the MTC course. Haplotype analysis in sMTC patients has shown an incomplete linkage equilibrium of the c.2307T $>\mathrm{G}$ variant with c. $2508 \mathrm{C}>\mathrm{T}\left(\mathrm{D}^{\prime}=1.000\right.$ but $\left.r^{2}=0.135\right)$.

Several studies have pointed out to c.2508C>T (p.S836S, rs1800862), a synonymous variant in exon 14,
(C) 2018 Society for Endocrinology Published by Bioscientifica Ltd. Printed in Great Britain 


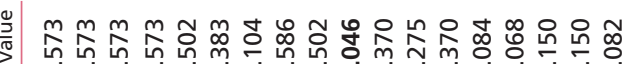

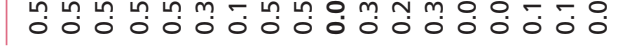

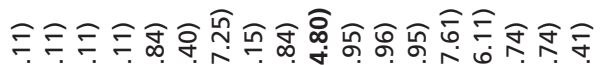

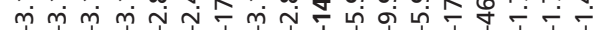

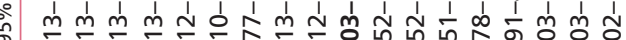

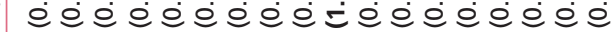

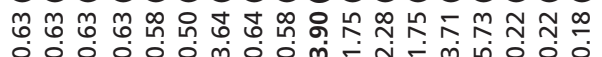

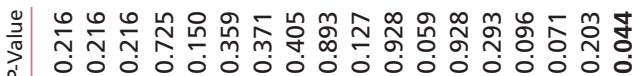

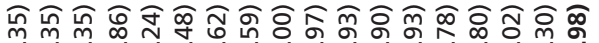

-

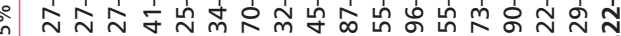

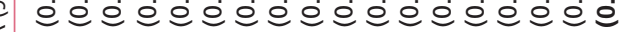

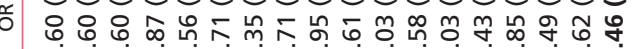

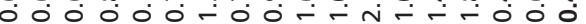

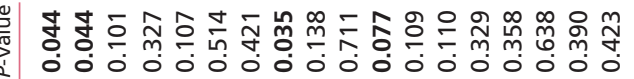

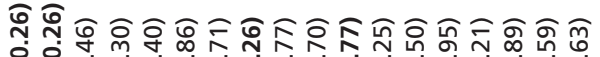

บิ 응 m

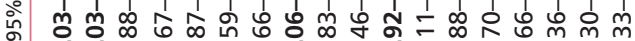

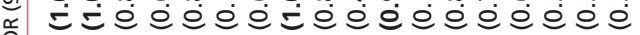

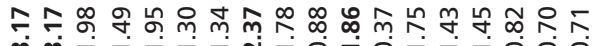

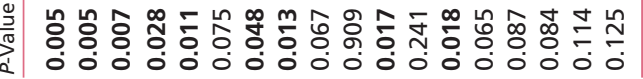

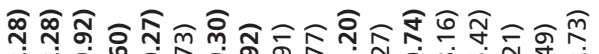

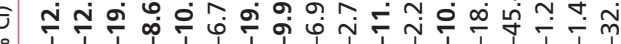

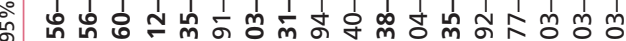

EE E E

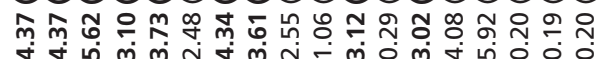

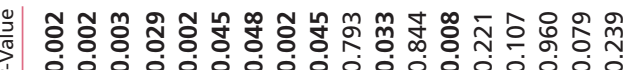

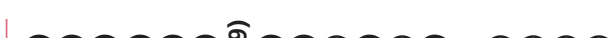

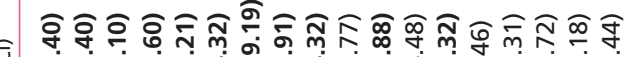

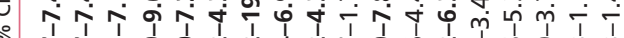

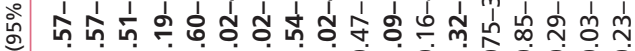

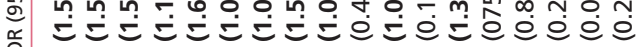

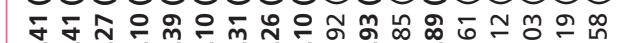

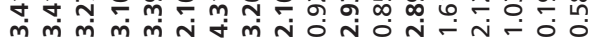

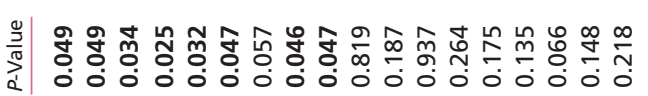

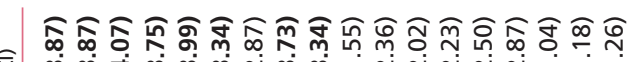

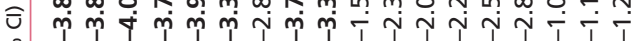

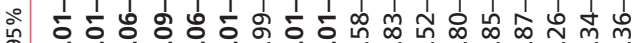

o $=\dot{5}=\dot{5}=\dot{=}=00000000$

ํํㅇ

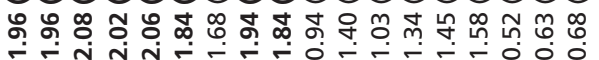


Table 6 Mutations in the RET gene against the haplotype background in hereditary medullary thyroid carcinoma patients.

\begin{tabular}{llll}
\multicolumn{2}{l}{ Haplotypes } & & \\
${$\cline { 1 - 1 }$>\mathrm{C}} }$ & $\mathrm{c.135 \textrm {G } > \mathrm { A }}$ & & $\mathrm{c.2307T}>\mathrm{G}$ \\
$\mathrm{C}$ & $\mathrm{G}$ & $\mathrm{T}$ \\
$\mathrm{T}$ & $\mathrm{A}$ & $\mathrm{G}$
\end{tabular}

$\mathrm{Cl}$, confidence interval; OR, odds ratio.

\begin{tabular}{|c|c|}
\hline \multicolumn{2}{|c|}{ p.C634R mutation } \\
\hline OR $(95 \% \mathrm{Cl})$ & $P$-Value \\
\hline 5.65 & $<0.001$ \\
\hline $0.11(0.03-0.04)$ & $<0.001$ \\
\hline
\end{tabular}

\begin{tabular}{|c|c|}
\hline Mutations at codon & 1, 804 \\
\hline OR $(95 \% \mathrm{Cl})$ & $P$-Value \\
\hline $0.16(0.06-0.47)$ & $<0.001$ \\
\hline $4.50(1.54-13.18)$ & 0.006 \\
\hline
\end{tabular}

as being associated with an increased risk of sporadic MTC (Fugazzola et al. 2008, Siqueira et al. 2010). In a Spanish and German population, this variant has been shown to be concomitant with a nearly threefold increase in the risk of sMTC, and it was most frequently detected in patients with the p.M918T somatic mutation (Gimm et al. 1999, Ruiz et al. 2001). In contrast, Machens et al. (2012) did not reported a significant association of c. $2508 \mathrm{C}>\mathrm{T}$ variant with an increased risk of sMTC in their group of German patients.

In this study, we have not found the c.2508T allele among hereditary MTC patients admitting that patient cohort is relatively small for studying a rare polymorphic variant. Among sporadic cases, the c.2508T allele was present at a $4.4 \%$ frequency, implying its role as a risk factor for sMTC, but the frequency in controls was similar $(3.4 \%)$, so it does not seem to be the case.

Ceolin et al. (2012) found that c.2508C>T and c.2307T $>$ G polymorphic variants are associated with an increased risk of sMTC in the Brazilian population. The adjusted OR for individuals with haplotypes including three or more polymorphic alleles was 3.79. No significant associations between the observed RET gene variants and disease onset or tumor size were noticed. In contrast, patients carrying haplotypes with three or four risk alleles had a nearly sixfold $(\mathrm{OR}=5.84)$ higher risk of lymph node involvement and distant metastases at the time of diagnosis. The results of these studies showed an additive effect of the described polymorphic variants on the risk of developing an aggressive MTC. In their last report, Ceolin et al. (2016) have shown that the c. $2508 \mathrm{C}>\mathrm{T}$ variant is in a strong LD with RET 3'UTR variants. They also performed an in silico analysis, which indicated that 3 'UTR variants may affect the secondary structure of RET mRNA and posttranscriptional processing. In the same line, polymorphisms closer to the $3^{\prime}$ region of the RET gene and metastases appeared to be associated in our study, but this result was borderline significant.

Our haplotype analysis has shown that the C-G-AG-T-(C)-C (c.73+9277T>C - c.135G>A - c.1296A>G c. $2071 \mathrm{G}>\mathrm{A}-$ c. $2307 \mathrm{~T}>\mathrm{G}-($ c. $2508 \mathrm{C}>\mathrm{T})-$ c. $2712 \mathrm{C}>\mathrm{G})$ allele combination predisposes to pheochromocytoma. Among carriers of this haplotype, twice as many individuals developed pheochromocytoma by the age of 40 years.

This haplotype was also three times more frequent in patients with multifocal MTC and its carriers had PHPT four times more often than non-carriers. This may indicate that this haplotype is associated with the MEN2A syndrome, and identifying it in young patients may be a predictive marker for early adrenal and parathyroid glands diagnostics. This is of great importance because pheochromoctytoma and PHPT when untreated are a real threat to patients' lives, greater than the MTC itself.

This study is the first one to report on RET mutations in association with the haplotypes. Our results indicate a strong relationship between mutations in codon 634 and the C-G-T (c.73+9277T>C - c.135G >A - c.2307T>G) allele arrangement. For the most frequent mutation: p.C634R, this association has been even stronger, whereas mutations related to isolated MTC (p.E768D, p.Y791F, p.V804M, p.R844Q) co-existed rarely with the C-G-T haplotype block and frequently with the alternative T-A-G combination. The co-occurrence of the p.E768D, p.Y791F, p.V804M or p.R844Q RET mutations with the c.73+9277T allele, which lowers the RET gene expression may be associated with a further attenuation of those weaker activating mutations and milder clinical picture of the disease.

In conclusion, it seems that the c.73+9277T $>C$ variant associated with alteration in activity of the $R E T$ enhancer, the c.73+9277T>C - c.135G >A - c.2307T>G alleles combination, or another sequence variant in LD with these polymorphisms may modify the clinical course of the MTC and the MEN2A syndrome. From the clinical point of view, determining this haplotype could help to predict the disease course and define the optimal age for prophylactic thyroidectomy in patients with RET mutations defined as moderate risk ('MOD') by the 2015 American Thyroid Association (ATA) recommendations (Wells 2015). Haplotype defining may also become a powerful diagnostic tool for the early presence of pheochromocytoma and primary hyperparathyroidism in MEN2A patients. 


\section{Supplementary data}

This is linked to the online version of the paper at https://doi.org/10.1530/ ERC-17-0452.

\section{Declaration of interest}

The authors declare that there is no conflict of interest that could be perceived as prejudicing the impartiality of the research reported.

\section{Funding}

This study was financially supported by the Polish Ministry of Science and Higher Education (grant no. NN402287436).

\section{Author contribution statement}

Marta Kaczmarek-Ryś designed the study and she is guarantor. Marta Kaczmarek-Ryś, Katarzyna Ziemnicka and Andrzej Pławski prepared the paper. Marta Kaczmarek-Ryś, Bartłomiej Budny, Szymon Hryhorowicz, Paweł Boruń, Justyna Hoppe-Gołębiewska and Maria Sromek contributed to the experimental and laboratory work. Katarzyna Ziemnicka, Monika Gołąb and Małgorzata Czetwertyńska were responsible for patients' clinical examination and qualification to the study. Marta KaczmarekRyś and Marlena Szalata performed statistical calculations and Michał Michalak consulted and supervised statistical analysis of the data. Marek Ruchała and Ryszard Słomski coordinated the whole research. All authors revised the paper critically for intellectual content and approved the final version. All authors agree to be accountable for the work and to ensure that any questions relating to the accuracy and integrity of the paper are investigated and properly resolved.

\section{References}

Barrett JC, Fry B, Maller J \& Daly MJ 2005 Haploview: analysis and visualization of LD and haplotype maps. Bioinformatics 21 263-265. (https://doi.org/10.1093/bioinformatics/bth457)

Baumgartner-Parzer SM, Lang R, Wagner L, Heinze G, Niederle B, Kaserer K, Waldhausl W \& Vierhapper H 2005 Polymorphisms in exon 13 and intron 14 of the RET protooncogene: genetic modifiers of medullary thyroid carcinoma? Journal of Clinical Endocrinology and Metabolism 90 6232-6236. (https://doi.org/10.1210/jc.2005-1278)

Berard I, Kraimps JL, Savagner F, Murat A, Renaudin K, Nicolli-Sire P, Bertrand G, Moisan JP \& Bezieau S 2004 Germline-sequence variants S836S and L769L in the RE arranged during Transfection (RET) proto-oncogene are not associated with predisposition to sporadic medullary carcinoma in the French population. Clinical Genetics $\mathbf{6 5}$ 150-152. (https://doi.org/10.1111/j.0009-9163.2004.00172.x)

Borrego S, Sáez ME, Ruiz A, Gimm O, López-Alonso M, Antiñolo G \& Eng C 1999 Specific polymorphisms in the RET proto-oncogene are over-represented in patients with Hirschsprung disease and may represent loci modifying phenotypic expression. Journal of Medical Genetics 36 771-774. (https://doi.org/10.1136/jmg.36.10.771)

Boruń P, Sowiński J, Ziemnicka K, Kubaszewski L, Lipinski D \& Pławski A 2012 Absence of the RET+3:T allele in the MTC patients. Hereditary Cancer in Clinical Practice 10 14. (https://doi.org/10.1186/1897-428710-14)

Cardot-Bauters C, Leteurtre E, Leclerc L, Vantyghem MC, Do Cao C, Wemeau JL, d'Herbomez M, Carnaille B, Barbu V, Pinson S, et al. 2008 Does the RET variant G691S influence the features of sporadic medullary thyroid carcinoma? Clinical Endocrinology 69 506-510. (https://doi.org/10.1111/j.1365-2265.2008.03230.x)

Carter TC, Kay DM, Browne ML, Liu A, Romitti PA, Kuehn D, Conley MR, Caggana M, Druschel CM, Brody LC, et al. 2012 Hirschsprung's disease and variants in genes that regulate enteric neural crest cell proliferation, migration and differentiation. Journal of Human Genetics $\mathbf{5 7}$ 485-493. (https://doi.org/10.1038/jhg.2012.54)

Cebrian A, Lesueur F, Martin S, Leyland J, Ahmed S, Luccarini C, Smith PL, Luben R, Whittaker J, Pharoah PD, et al. 2005 Polymorphisms in the initiators of RET (rearranged during transfection) signaling pathway and susceptibility to sporadic medullary thyroid carcinoma. Journal of Clinical Endocrinology and Metabolism 90 6268-6274. (https://doi.org/10.1210/jc.2004-2449)

Ceolin L, Rodrigues Siqueira D, Vaz Ferreira C, Romitti M, Maia SC, Leiria L, Crispim D, Ashton-Prolla P \& Maia AL 2012 Additive effect of RET polymorphisms on sporadic medullary thyroid carcinoma susceptibility and tumor aggressiveness. European Journal of Endocrinology 166 847-854. (https://doi.org/10.1530/EJE-11-1060)

Ceolin L, Romitti M, Siqueira DR, Vaz Ferreira C, Oliboni Scapineli J, Assis-Brazil B, Vieira Maximiano R, Dias Amarante T, de Souza Nunes MC, Weber G, et al. 2016 Effect of 3'UTR RET variants on RET mRNA secondary structure and disease presentation in medullary thyroid carcinoma. PLOS ONE 11 e0147840. (https://doi.org/10.1371/ journal.pone.0147840)

Da Silva AM, Maciel RM, Da Silva MR, Toledo SR, De Carvalho MB \& Cerutti JM 2003 A novel germ-line point mutation in RET exon 8 (Gly(533)Cys) in a large kindred with familial medullary thyroid carcinoma. Journal of Clinical Endocrinology and Metabolism $\mathbf{8 8}$ 5438-5443. (https://doi.org/10.1210/jc.2003-030997)

Deeks JJ \& Higgins JPT 2010 Statistical algorithms in Review Manager 5. London, UK: Cochrane Collaboration Statistical Methods Group. (available at: http://imaging.mrc-cbu.cam.ac.uk/statswiki/FAQ/meta? action=AttachFile\&do=get\&target=cochraneor.pdf)

Donahue TR \& Hines OJ 2009 CXCR2 and RET single nucleotide polymorphisms in pancreatic cancer. World Journal of Surgery $\mathbf{3 3}$ 710-715 (https://doi.org/10.1007/s00268-008-9826-z)

Elisei R, Cosci B, Romei C, Bottici V, Sculli M, Lari R, Barale R, Pacini F \& Pinchera A 2004 RET exon 11 (G691S) polymorphism is significantly more frequent in sporadic medullary thyroid carcinoma than in the general population. Journal of Clinical Endocrinology and Metabolism 89 3579-3584. (https://doi. org/10.1210/jc.2003-031898)

Elisei R, Romei C, Cosci B, Agate L, Bottici V, Molinaro E, Sculli M, Miccoli P, Basolo F, Grasso L, et al. 2007 RET genetic screening in patients with medullary thyroid cancer and their relatives: experience with 807 individuals at one center. Journal of Clinical Endocrinology and Metabolism 92 4725-4729. (https://doi. org/10.1210/jc.2007-1005)

Emison ES, McCallion AS, Kashuk CS, Bush RT, Grice E, Lin S, Portnoy ME, Cutler DJ, Green ED \& Chakravarti A 2005 A common sex-dependent mutation in a RET enhancer underlies Hirschsprung disease risk. Nature 434 857-863. (https://doi.org/10.1038/ nature03467)

Emison ES, Garcia-Barcelo M, Grice EA, Lantieri F, Amiel J, Burzynski G, Fernandez RM, Hao L, Kashuk C, West K, et al. 2010 Differential contributions of rare and common, coding and noncoding Ret mutations to multifactorial Hirschsprung disease liability. American Journal of Human Genetics 87 60-74. (https://doi.org/10.1016/j. ajhg.2010.06.007)

Fernández RM, Navarro E, Antiñolo G, Ruiz-Ferrer M \& Borrego S 2006a Evaluation of the role of RET polymorphisms/haplotypes as modifier loci for MEN 2, and analysis of the correlation with the type of RET mutation in a series of Spanish patients. International Journal of Molecular Medicine 17 575-581. (https://doi.org/10.3892/ ijmm.17.4.575) (c) 2018 Society for Endocrinology Published by Bioscientifica Ltd. Printed in Great Britain 
Fernández RM, Peciña A, Antiñolo G, Navarro E \& Borrego S 2006b Analysis of RET polymorphisms and haplotypes in the context of sporadic medullary thyroid carcinoma. Thyroid 16 411-417. (https:// doi.org/10.1089/thy.2006.16.411)

Figlioli G, Landi S, Romei C, Elisei R \& Gemignani F 2013 Medullary thyroid carcinoma (MTC) and RET proto-oncogene: mutation spectrum in the familial cases and a meta-analysis of studies on the sporadic form. Mutation Research 752 36-44. (https://doi. org/10.1016/j.mrrev.2012.09.002)

Fugazzola L, Muzza M, Mian C, Cordella D, Barollo S, Alberti L, Cirello V, Dazzi D, Girelli ME, Opocher G, et al. 2008 RET genotypes in sporadic medullary thyroid cancer: studies in a large Italian series. Clinical Endocrinology 69 418-425. (https://doi. org/10.1111/j.1365-2265.2008.03218.x)

Gimm O, Neuberg DS, Marsh DJ, Dahia PL, Hoang-Vu C, Raue F Hinze R, Dralle H \& Eng C 1999 Over-representation of a germline RET sequence variant in patients with sporadic medullary thyroid carcinoma and somatic RET codon 918 mutation. Oncogene 18 1369-1373. (https://doi.org/10.1038/sj.onc.1202418)

Griseri P, Garrone O, Lo Sardo A, Monteverde M, Rusmini M, Tonissi F, Merlano M, Bruzzi P, Lo Nigro C \& Ceccherini I 2016 Genetic and epigenetic factors affect RET gene expression in breast cancer cell lines and influence survival in patients. Oncotarget $726465-26479$. (https://doi.org/10.18632/oncotarget.8417)

Lantieri F, Caroli F, Ceccherini I \& Griseri P 2013 The involvement of the RET variant G691S in medullary thyroid carcinoma enlightened by a meta-analysis study. International Journal of Cancer 132 2808-2819. (https://doi.org/10.1002/ijc.27967)

Machens A, Frank-Raue K, Lorenz K, Rondot S, Raue F \& Dralle H 2012 Clinical relevance of RET variants G691S, L769L, S836S and S904S to sporadic medullary thyroid cancer. Clinical Endocrinology 76 691-697. (https://doi.org/10.1111/j.1365-2265.2011.04293.x)

Pan ZW \& Li JC 2012 Advances in molecular genetics of Hirschsprung's disease. Anatomical Record 295 1628-1638 (https://doi.org/10.1002/ ar.22538)

Qi XP, Ma JM, Du ZF, Ying RB, Fei J, Jin HY, Han JS, Wang JQ, Chen XL, Chen CY, et al. 2011 RET germline mutations identified by exome sequencing in a Chinese multiple endocrine neoplasia type $2 \mathrm{~A} /$ familial medullary thyroid carcinoma family. PLOS ONE 6 e20353. (https://doi.org/10.1371/journal.pone.0020353)

Robledo M, Gil L, Pollán M, Cebrián A, Ruíz S, Azañedo M, Benitez J, Menárguez J \& Rojas JM 2003 Polymorphisms G691S/S904S of RET as genetic modifiers of MEN 2A. Cancer Research 63 1814-1817.

Ruiz A, Antinolo G, Fernandez RM, Eng C, Marcos I \& Borrego S 2001 Germline sequence variant S836S in the RET proto-oncogene is associated with low level predisposition to sporadic medullary thyroid carcinoma in the Spanish population. Clinical Endocrinology 55 399-402. (https://doi. org/10.1046/j.1365-2265.2001.01328.x)

Sarika HL, Papathoma A, Garofalaki M, Vasileiou V, Vlassopoulou B, Anastasiou E \& Alevizaki M 2012 High prevalence of exon 8 G533C mutation in apparently sporadic medullary thyroid carcinoma in Greece. Clinical Endocrinology 77 857-862. (https://doi. org/10.1111/j.1365-2265.2012.04462.x)

Sarika HL, Papathoma A, Garofalaki M, Saltiki K, Pappa T, PazaitouPanayiotou K, Anastasiou E \& Alevizaki M 2015 Genetic screening of patients with medullary thyroid cancer in a referral center in Greece during the past two decades. European Journal of Endocrinology 172 501-509. (https://doi.org/10.1530/EJE-14-0817)

Sawai H, Okada Y, Kazanjian K, Kim J, Hasan S, Hines OJ, Reber HA, Hoon DS \& Eibl G 2005 The G691S RET polymorphism increases glial cell line-derived neurotrophic factor-induced pancreatic cancer cell invasion by amplifying mitogen-activated protein kinase signaling. Cancer Research 65 11536-11544. (https://doi. org/10.1158/0008-5472.CAN-05-2843)

Siqueira DR, Romitti M, da Rocha AP, Ceolin L, Meotti C, Estivalet A, Punales MK \& Maia A 2010 The RET polymorphic allele S836S is associated with early metastatic disease in patients with hereditary or sporadic medullary thyroid carcinoma. Endocrine-Related Cancer 17 953-963. (https://doi.org/10.1677/ERC-09-0312)

Słomski R, Szalata M, Wolko Ł \& Wielgus K 2008 Izolacja DNA. In Analiza DNA, pp 44-53. Eds R Słomski. Poznań, Poland: Wydawnictwo Uniwersytetu Przyrodniczego.

Sosonkina N, Hong SK, Starenki D \& Park JI 2014 Kinome sequencing reveals RET G691S polymorphism in human neuroendocrine lung cancer cell lines. Genes and Genomics 36 829-841. (https://doi. org/10.1007/s13258-014-0217-6)

Sromek M, Czetwertyńska M, Skasko E, Zielińska J, Czapczak D \& Steffen J 2010 The frequency of selected polymorphic variants of the RET gene in patients with medullary thyroid carcinoma and in the general population of central Poland. Endocrine Pathology 21 178-185. (https://doi.org/10.1007/s12022-010-9125-8)

Vaclavikova E, Dvorakova S, Skaba R, Pos L, Sykorova V, Halkova T, Vcelak J \& Bendlova B 2014 RET variants and haplotype analysis in a cohort of Czech patients with Hirschsprung disease. PLOS ONE 9 e98957. (https://doi.org/10.1371/journal.pone.0098957)

Wells SA Jr, Asa SL, Dralle H, Elisei R, Evans DB, Gagel RF, Lee N, Machens A, Moley JF, Pacini F, et al. 2015 Revised American Thyroid Association guidelines for the management of medullary thyroid carcinoma. Thyroid 25 567-610. (https://doi.org/10.1089/ thy.2014.0335)

Received in final form 23 January 2018

Accepted 31 January 2018

Accepted Preprint published online 31 January 2018 (c) 2018 Society for Endocrinology Published by Bioscientifica Ltd. Printed in Great Britain 